\title{
Upper Gastrointestinal Stent Insertion in Malignant and Benign Disorders
}

\author{
Hyoun Woo Kang ${ }^{1}$ and Sang Gyun Kim² \\ ${ }^{1}$ Department of Internal Medicine, Dongguk University Ilsan Hospital, Dongguk University College of Medicine, Goyang, ${ }^{2}$ Department of Internal \\ Medicine and Liver Research Institute, Seoul National University College of Medicine, Seoul, Korea
}

Upper gastrointestinal (GI) stents are increasingly being used to manage upper GI obstructions. Initially developed for palliative treatment of esophageal cancer, upper GI stents now play an emerging role in benign strictures of the upper GI tract. Because recurrent obstruction and stent-related complications are common, new modifications of stents have been implemented. Self-expandable metal stents (SEMS) have replaced older plastic stents. In addition, newly designed SEMS have been developed to prevent complications. This review provides an overview of the various types, indications, methods, complications, and clinical outcomes of upper GI stents in a number of malignant and benign disorders dividing the esophagus and gastroduodenum.

Key Words: Upper gastrointestinal tract; Stents; Obstruction; Malignant; Benign

\section{INTRODUCTION}

Upper gastrointestinal (GI) stents are devices used to maintain bowel luminal patency, thereby increasing nutrition intake and improving quality of life. ${ }^{1,2}$ Upper GI stents have mainly been developed to alleviate malignant obstructions caused by esophageal cancer, gastric cancer, periampullary cancer, or other malignancies that directly invade the upper GI tract. Disadvantages of GI stents are recurrent obstruction and stentrelated complications. In the last decade, studies in this area have focused mostly on modifying stent design to improve efficacy and safety. In addition, indications for upper GI stents have widened to include benign diseases, such as benign stricture and perforation. However, most studies in this area are small and uncontrolled. The optimal indications, methods, and duration of therapy for these disorders remain to be determined.

This review provides an overview of upper GI stenting in the esophagus and gastroduodenum, with an emphasis on the

Received: April 19, 2015 Accepted: April 22, 2015

Correspondence: Sang Gyun Kim

Department of Internal Medicine and Liver Research Institute, Seoul National University College of Medicine, 101 Daehak-ro, Jongno-gu, Seoul 110-744, Korea Tel: +82-2-740-8112, Fax: +82-2-743-6701, E-mail: harley@snu.ac.kr

(c) This is an Open Access article distributed under the terms of the Creative Commons Attribution Non-Commercial License (http://creativecommons.org/ licenses/by-nc/3.0) which permits unrestricted non-commercial use, distribution, and reproduction in any medium, provided the original work is properly cited. indications, methods, complications, and clinical outcomes.

\section{TYPES OF STENTS}

Upper GI stents were originally designed as rigid cylinders, resulting in poor efficacy and high complication rates. In recent decades, several types of flexible and self-expandable stents have been developed. Currently available upper GI stents include self-expandable metal stents (SEMS) for esophageal and gastroduodenal obstructions and self-expandable plastic stents (SEPS) for esophageal obstructions. ${ }^{3}$ Metal stents, made of stainless steel and alloys such as nitinol and Elgiloy (Elgiloy Specialty Metals, Elgin, IL, USA), have a higher degree of flexibility and are capable of generating high radial forces to maintain stent patency and position. Nitinol is an alloy of nickel and titanium and is most commonly used as a material for SEMS. It possesses good shape-memory properties and flexibility. ${ }^{4}$ SEMS are available as uncovered, partially covered, or fully covered with a coating, usually a plastic membrane or silicone. ${ }^{3}$ SEPS are composed of polyester and silicone and are indicated for the treatment of malignant esophageal obstructions. Although there were no differences in the clinical outcomes using SEPS and SEMS in terms of symptom relief, complications, or survival, the insertion of SEPS is technically more difficult, with a higher migration rate than that of SEMS in esophageal malignant obstructions. ${ }^{5,6}$ Each type 
of stent has its own inherent optimal indications, advantages, and disadvantages in clinical situations (Table 1).

Stent innovations include antireflux and antimigration features. Antireflux features were especially developed for stents through the lower esophageal sphincter. Generally, a one-way valve was attached to the distal end of the stent, inhibiting reflux from gastric contents into the esophagus. Although some studies indicated that reflux symptoms improved with the use of anti-reflux stents, a meta-analysis did not identify any significant differences in reflux symptoms, complications, or quality of life. ${ }^{7}$ Moreover, as this type of stent is covered, it migrates more frequently. Therefore, the use of anti-reflux stents has been all but abandoned. Antimigration stents have properties such as a metal mesh, wider diameter with stent flares, full double-layered coverage, and antimigration rings on the outer surface, such as anchoring devices. However, several studies did not find any significant differences in migration. ${ }^{8,9}$ Moreover, frequent recurrent obstruction and complications were reported..$^{10,11}$

\section{ESOPHAGEAL STENTS}

\section{Indications}

The goals of stent placement are to provide relief from obstructive symptoms, allow the patient to resume a diet, and improve the patient's quality of life. As such, stent placement is not indicated for asymptomatic patients with upper GI obstructions who can tolerate a normal diet. Other contraindications to stent placement are the presence of multiple bowel obstruction sites (since stenting the proximal obstruction is unlikely to provide symptom improvement) and the presence of free perforations.

The indications for esophageal stents include malignant or benign diseases in the esophagus, gastroesophageal junction, and gastric cardia. The earliest indication for a GI stent was a malignant obstruction by esophageal cancer and gastric cardia cancer. Extrinsic tumor invasion or compression may also be another indication. Recently, the use of esophageal stents has increased to include benign strictures (peptic, caustic, and radiation-induced), postoperative leaks, iatrogenic perforations, tracheoesophageal fistulas, and refractory esophageal variceal bleeding. Palliative care of inoperable malignant obstruction remains the most common indication for esophageal stenting (Table 2).

\section{Methods}

During stent selection for esophageal obstruction, the location of the obstruction, length of stent, and type of stent should be considered. For upper obstructions, the use of esophageal stents is considered to relatively contraindicative due to the risk of intolerable foreign body sensations, pulmonary aspiration, and migration into the hypopharynx. Modified stents with a shorter flange and an obtuse angle may be beneficial in preventing cervical esophageal obstruction. ${ }^{12,13}$ Due shortening of stents after deployment, it is important to select a stent length of at least $4 \mathrm{~cm}$ longer than the length of the stricture. This increases the likelihood of an adequate margin at the proximal and distal ends of the obstruction.

Given the potential risk of airway compression with stent expansion, esophageal stent insertion is frequently performed via endoscopy under sedation. Standard procedural sedation with an opiate and benzodiazepine is usually sufficient. The monitoring of blood pressure and oxygen saturation is important, and the patient should be placed in the left lateral decubitus or prone position to minimize the risk of aspiration due to retained gastric contents. The prone position allows for

Table 1. Comparison of the Indications, Advantages, and Disadvantages of Different Types of Stents

\begin{tabular}{|c|c|c|c|}
\hline Types of stent & Appropriate indications & Advantages & Disadvantage \\
\hline Uncovered SEMS & $\begin{array}{l}\text { Expected poor survival } \\
\text { High risk of migration } \\
\text { Gastroduodenal obstruction to avoid } \\
\text { obstructing biliary drainage }\end{array}$ & Low risk of migration & $\begin{array}{l}\text { High risk of tumor ingrowth } \\
\text { Difficult removal }\end{array}$ \\
\hline $\begin{array}{l}\text { Partially covered } \\
\text { SEMS }\end{array}$ & $\begin{array}{l}\text { High risk of migration in patient otherwise } \\
\text { suitable for fully covered SEMS }\end{array}$ & $\begin{array}{l}\text { Intermediate risk of migration and } \\
\text { tumor ingrowth }\end{array}$ & $\begin{array}{l}\text { Intermediate risk of tumor ingrowth } \\
\text { Difficult removal }\end{array}$ \\
\hline $\begin{array}{l}\text { Fully covered } \\
\text { SEMS }\end{array}$ & $\begin{array}{l}\text { High risk of tumor ingrowth } \\
\text { Temporary measure: benign stricture }\end{array}$ & $\begin{array}{l}\text { Low risk of tumor ingrowth } \\
\text { Easy removal }\end{array}$ & High risk of migration \\
\hline SEPS & $\begin{array}{l}\text { Benign esophageal stricture } \\
\text { Temporary measure }\end{array}$ & $\begin{array}{l}\text { Safe and easy removal } \\
\text { No tumor ingrowth }\end{array}$ & $\begin{array}{l}\text { High risk of migration } \\
\text { Complex and stiff stent introducer } \\
\text { system } \\
\text { High rate of stent failure requiring } \\
\text { reintervention }\end{array}$ \\
\hline
\end{tabular}

SEMS, self-expandable metal stent; SEPS, self-expandable plastic stent. 
Table 2. Indication for Stent Insertion in the Upper Gastrointestinal Tract

\begin{tabular}{lll}
\hline \multicolumn{1}{c}{ Site } & \multicolumn{1}{c}{ Benign disorders } & \multicolumn{1}{c}{ Malignant disorders } \\
\hline Esophagus & Benign stricture & Esophageal cancer \\
& Esophageal perforation & Gastric cardia cancer \\
& Esophagobronchial fistula & Extrinsic tumor invasion or compression such as lung cancer, mediastinal \\
& Refractory esophageal & cancer, metastatic cancer \\
& Variceal bleeding & \\
Genign stricture (possible) & Gastric cancer \\
& & Duodenal cancer \\
& & Pancreatic cancer \\
\hline
\end{tabular}

a better anatomic view under fluoroscopy. The supine position should be avoided unless the patient is endotracheally intubated due to the risk of aspiration. First, the length of stenosis should be estimated by endoscopy, fluoroscopy, or computed tomography prior to stent insertion. When estimation of the length of stenosis is impossible, a stent long enough to provide complete coverage of the full stricture should be selected. Second, a guide-wire is inserted through the obstructive lesion, with or without fluoroscopic guidance, at least 20 $\mathrm{cm}$ distal to the obstruction. ${ }^{12,14}$ Adequate insertion of the guide-wire can be confirmed by fluoroscopy and loss of resistance to the guide-wire. Third, the stent is inserted through the guide-wire up to roughly $2 \mathrm{~cm}$ proximal to the obstructive lesion. To assist adequate stent deployment, the proximal and distal ends of the stent are marked accordingly with radiopaque markers. Finally, the delivery device is withdrawn with endoscopic guidance, maintaining the stent in place. Complete stent expansion usually occurs within 24 to 48 hours, although very tight strictures may lead to longer or incomplete expansion. Patients are permitted to ingest liquids following the procedure and, subsequently, cautiously advance to a low-residue diet. ${ }^{15}$ The diet can start gradually from water to a regular diet within 24 to 48 hours following stent insertion. ${ }^{4}$ Afterward, simple radiography should be used to confirm proper location and expansion of the stent.

\section{Complications}

Potential stent-related complications include recurrent obstruction due to tumor ingrowth, perforation, stent migration, bronchoesophageal fistulas, and retrosternal pain.

Recurrent obstruction occurs in almost $30 \%$ of patients and develops most often due to tumor ingrowth and food impaction. In case of tumor ingrowth, insertion of a second stent is effective in restoring luminal patency. ${ }^{16,17}$ This complication can also result from stent migration. Endoscopic repositioning or reinsertion of a new stent may be preferable. Obstruction by impacted food can be managed by endoscopic clearance. Another rare late complication is stent fracture, resulting in recurrent obstruction. In this situation, stent-in-stent inser- tion appears to be safe and effective. Endoscopic removal of fractured stents is also possible. ${ }^{17}$

Migration is more common for covered stents than uncovered stents. The reported rate of migration is $10 \%$ to $25 \%$ for covered stents and 2\% to 5\% for uncovered stents. Migration can reportedly be prevented by clipping of the proximal end to the esophageal wall. ${ }^{18}$

Iatrogenic esophageal perforations are life-threatening, with a high rate of morbidity and mortality. Surgical treatment for these patients is associated with poor outcomes. ${ }^{19}$ Stent-associated esophagobronchial fistulas occurs most frequently several months after stent insertion. A recent retrospective study reported that stent-associated esophagobronchial fistulas developed in $4 \%$ of patients with esophageal stenting. ${ }^{20}$ Additional insertion of a fully covered SEMS is an effective treatment modality in this case.

Retrosternal pain occurs in $13 \%$ to $60 \%$ of patients. ${ }^{2,21}$ Pain continues for an average of 10 days, becoming tolerable in most patients with the administration of analgesics without the need for stent removal.

\section{Clinical outcome}

Over the last 15 years, six randomized trials comparing different stents in patients with malignant esophageal obstructions have been published. ${ }^{22-27}$ Technical success is defined as successful insertion and adequate placement of the stent. Clinical success is the palliation of dysphagia. The technical and clinical success rates in these studies were $83 \%$ to $100 \%$ and $80 \%$ to $95 \%$, respectively. In previous studies, the rate of recurrent dysphagia was reported to be $8 \%$ to $52 \%$. The median duration of esophageal stent patency was reported to be $94 \%$ at 4 weeks, $78 \%$ at 3 months, and $67 \%$ at 6 months. Major complications, including perforation, aspiration pneumonia, stridor, and overt hemorrhaging, were reported for $8 \%$ to $36 \%$ of cases. A recent study showed that insertion of a novel esophageal stent coated with ${ }^{125} \mathrm{I}$ seeds provided relief from dysphagia and prolonged survival compared to a conventional covered SEMS in patients with unresectable esophageal cancer. $^{27}$ 
In benign strictures, the mainstay of management has been endoscopic balloon dilation. ${ }^{28}$ Efficacy varies depending on the etiology of the strictures and clinical improvement in anastomotic, caustic, peptic, and radiation-induced strictures has been reported to be $92 \%, 84 \%, 81 \%$, and $58 \%$, respectively. ${ }^{29}$ However, patients with complex strictures have a high risk of persistent or recurrent strictures. The concept of an esophageal stent in refractory strictures depends on continuous dilation of the stricture site for at least 6 weeks, causing sustained luminal patency after stent removal. Various types of stents have been explored for this indication, including extractable SEMS, SEPS, and biodegradable stents. Overall, sustained improvement of dysphagia was achieved in approximately $50 \%$ of patients. ${ }^{30}$ Long-term efficacy of SEPS was not found to be different compared with SEMS in terms of relief of dysphagia, although migration rate was higher. In the largest prospective study, stent migrations were observed in $22 \%$ of patients. ${ }^{31}$ Moreover, SEPS were associated with frequent complications, including severe chest pain, perforation, fistulas, and bleeding. ${ }^{32,33}$ Biodegradable stents do not require removal. Several studies have evaluated these stents in refractory benign strictures. ${ }^{34-36}$ In the largest study, recurrent dysphagia occurred in 21 of 28 patients at a median of 90 days and was caused by recurrent strictures, stent migration, and food impaction. ${ }^{37}$ Esophageal perforations are life-threatening, with a high rate of morbidity and mortality. ${ }^{38}$ Prompt intervention is therefore very important in the treatment of these patients. Insertion of a covered stent sealing the perforation site has evolved as a promising treatment modality. A systemic review showed perforation healing in $85 \%$ of cases, ${ }^{19}$ with an overall mortality of $13 \%$, lower than reported in surgical treatment. Refractory esophageal variceal bleeding after a failed endoscopic variceal ligation is another interesting indication for esophageal SEMS insertion. The efficacy and safety of specially designed stents (SX-Ella stent Danis; Ella-CS, Hradec Kralove, Czech Republic) has been evaluated in several case series. ${ }^{39-42}$ Hemostasis was achieved in $77 \%$ to $100 \%$ of patients. Stent migration has been reported in up to $25 \%$ of cases, though endoscopic repositioning was feasible. These results suggest that stent insertion can be used in refractory esophageal variceal bleeding.

\section{GASTRODUODENAL STENTS}

\section{Indications}

Gastroduodenal obstruction causing gastric outlet obstruction is common in patients with malignancies of the stomach, duodenum, and pancreas. In the Western world, malignant gastric outlet obstruction occurs most commonly due to obstruction by pancreatic cancer. Malignant gastric obstruc- tions at the level of the stomach due to stomach cancer is seen in Asian countries, including Korea. ${ }^{43}$ These patients have nausea, vomiting, early satiety, weight loss, and a poor quality of life. Gastroduodenal stent placement is used to treat symptomatic patients with unresectable or recurrent malignancies at anastomotic sites. Patients considered for stent placement should have a short life expectancy (less than 2 to 6 months). ${ }^{44,45}$ As with other enteral stents, stent insertion is not indicated for asymptomatic patients with a gastric outlet obstruction and who tolerate a regular diet. Other contraindications to stent placement are the presence of multiple small bowel obstruction sites, since stenting the proximal stricture is unlikely to provide symptom relief, and the presence of free perforations. In addition, patients with peritoneal carcinomatosis may not respond as well to stent placement due to the risk of multiple obstruction sites, although some data suggest that stents can work in such patients. In a retrospective study of $215 \mathrm{pa}$ tients undergoing stent placement for malignant gastric outlet obstruction, 116 patients (60\%) had carcinomatosis and 76 ( $40 \%$ ) did not. ${ }^{46}$ Clinically successful outcomes ( $81 \%$ vs. $84 \%$, respectively), need for reintervention ( $18 \%$ vs. $27 \%$, respectively), and major complications ( $4 \%$ for both groups) were similar for those with and without carcinomatosis.

There have been several reports on gastroduodenal stenting in patients with benign gastroduodenal obstructions who have high risks in surgery. ${ }^{47-49}$ However, it seems premature to consider stent insertion as an alternative therapeutic modality for surgery or endoscopic balloon dilation due to frequent migration (Table 2).

\section{Methods}

It may be important to perform a radiographic study with computed tomography with oral contrast or an upper GI series to assess the anatomy, length of stricture, and degree of obstruction, especially in patients where it is unclear if the obstruction is functional. ${ }^{50}$ Other techniques are the same as with esophageal stents.

\section{Complications}

Several complications can occur during or after gastroduodenal stent insertion. ${ }^{51,52}$ Intraprocedural complications include those related to sedation, pulmonary aspiration, stent malposition, perforation, and bleeding. Late complications include stent migration, stent occlusion, fistula formation, perforation, bleeding, and occlusion of biliary stents.

In a systematic review of 606 patients, there was no procedure-related mortality. Severe adverse events, including bleeding and perforation, were observed in seven patients (1.2\%), stent migration in 31 patients (5\%), and stent obstruction in 104 cases (18\%), mainly due to tumor ingrowth. 
Obstruction of stents by tumor ingrowth of malignant or benign tissue is usually managed by the placement of additional stents through the original ones. ${ }^{53}$ There are currently no data concerning the safety of gastroduodenal stenting in patients who have undergone or are undergoing radiation therapy, a setting in which stenting may be more risky. ${ }^{50}$

Patients with a SEMS for a biliary obstruction who subsequently undergo duodenal stent placement are at an increased risk of biliary stent dysfunction. In a series of 410 patients with biliary stents, 33 underwent duodenal stent placement. ${ }^{52}$ Biliary stent dysfunction developed in 17 patients (52\%), showing that this procedure was a risk factor for biliary stent dysfunction.

\section{Clinical outcomes}

Stents can be placed successfully in over $90 \%$ of patients, with typical clinical success rates of $80 \%$ or higher. ${ }^{54-59}$ Technical failure is usually due to an inability to pass the guidewire through the stricture, anatomic difficulties such as severe looping within the dilated stomach, or complicated postsurgical anatomy. ${ }^{50}$ Published experiences with enteral stenting for gastroduodenal obstructions consist mostly of observational studies, ${ }^{54,57,58,60-69}$ although small randomized trials have compared stent placement with a surgical bypass for palliation of malignant gastric outlet obstruction. ${ }^{44,70,71}$ In one of these randomized trials, 39 patients with malignant gastric outlet obstruction were assigned to either gastrojejunostomy (18 patients) or enteral stent placement (21 patients). ${ }^{44}$ Food intake improved more rapidly in the stent group compared to the surgery group (median, 5 days vs. 8 days). Nevertheless, long-term relief was worse in the stent group (median duration of relief, 50 days vs. 72 days). Major complications were more common in the stent group, though there were no differences between the groups in survival or health-related quality of life scores. In a second randomized trial, 18 patients were assigned to endoscopic stent placement or surgical bypass. ${ }^{70}$ Endoscopic stenting was superior to surgery in the median operative time (40 minutes vs. 93 minutes), mean time to restoration of oral intake (2.1 days vs. 6.3 days), and median length of hospital stay (3.1 days vs. 10 days). There were no significant differences between the groups in morbidity, mortality, gastric emptying, or clinical outcomes at the 3-month follow-up. Observational studies suggest that enteral stenting has a success rate similar to that of surgical palliation, with approximately $90 \%$ of patients improving clinically, and is associated with lower morbidity, procedure-related mortality, and cost. $^{55,56,72-74}$ A database study comparing 425 stenting procedures with 339 surgical bypasses for malignant gastric outlet obstruction found that the median length of stay was shorter for stenting procedures than for surgery (8 days vs. 16 days) and the median cost was lower. ${ }^{74}$ Furthermore, some studies suggest that stenting may permit a better quality of life compared to other forms of palliation (such as non-oral feeding through a jejunostomy tube). ${ }^{75,76}$ Studies of one of the newer stents (Evolution Duodenal Stent) have found similar success rates. In a series of 46 patients, technical success was achieved in $89 \%$ of cases, with a clinical success rate of $72 \%{ }^{68}$

The following conclusions were obtained in a systematic review of 44 studies comparing stenting and gastrojejunostomy (1,046 patients receiving a stent, and 297 undergoing gastrojejunostomy). ${ }^{55}$ There were no significant differences between stent insertion and gastrojejunostomy in terms of technical success ( $96 \%$ vs. $100 \%$ ), early complications (7\% vs. $6 \%$ ), late major complications ( $18 \%$ vs. $17 \%)$, or persistent symptoms ( $8 \%$ vs. $9 \%)$. Initial clinical success was higher after stent placement ( $89 \%$ vs. $72 \%$ ), as were recurrent obstructive symptoms (18\% vs. 1\%). Mean survival was 105 days after stent placement and 164 days after gastrojejunostomy. Despite initial success, $15 \%$ to $40 \%$ of patients require reintervention for recurrent symptoms or biliary obstruction following stent placement. Reintervention rates were generally lower in patients undergoing gastrojejunostomy. ${ }^{44,55,69,73}$ Furthermore, some patients may not improve, even after successful stent placement. This may result from unidentified distal sites of malignant obstruction, diffuse peritoneal carcinomatosis with bowel encasement, or functional gastric outlet obstruction from neural (celiac axis) tumor involvement. ${ }^{15,50,77}$

In a prospective observational study of 22 patients undergoing SEMS for benign pyloric stenosis, early symptom improvement was achieved in 18 patients (81.9\%). However, during the follow-up period (mean 10.2 months), the stents remained in place in only seven patients (31.8\%). Among the 15 patients with stent migration, seven patients (46.6\%) showed continued symptom improvement without recurrent symptoms. ${ }^{78}$ However, most publications in the benign disease have small sample sizes and are uncontrolled. The optimal indications, methods, and duration of stenting for benign diseases should to be determined in further studies.

\section{CONCLUSIONS}

Endoscopic stent placement in upper GI disorders is currently the most common modality for palliation of symptoms in patients with malignant upper GI obstruction, replacing conventional surgical bypass. Endoscopic stenting is associated with less invasiveness, high compliance, less complications, shorter hospital stays, and lower costs. Although there have been several complications, such as migration and recurrent obstruction, newly developed stents are expected to overcome these limitations and extend to a variety of benign and malignant disorders. 


\section{Conflicts of Interest}

The authors have no financial conflicts of interest.

\section{REFERENCES}

1. Parrish CR. Nutrition concerns for the patient with gastroparesis. Curr Gastroenterol Rep 2007;9:295-302.

2. Didden P, Spaander MC, Bruno MJ, Kuipers EJ. Esophageal stents in malignant and benign disorders. Curr Gastroenterol Rep 2013;15:319.

3. Kochar R, Shah N. Enteral stents: from esophagus to colon. Gastrointest Endosc 2013;78:913-918.

4. Kim SG, Yang CH. Upper gastrointestinal stent. Clin Endosc 2012;45: 386-391.

5. Conigliaro R, Battaglia G, Repici A, et al. Polyflex stents for malignant oesophageal and oesophagogastric stricture: a prospective, multicentric study. Eur J Gastroenterol Hepatol 2007;19:195-203.

6. Szegedi L, Gál I, Kósa I, Kiss GG. Palliative treatment of esophageal carcinoma with self-expanding plastic stents: a report on 69 cases. Eur J Gastroenterol Hepatol 2006;18:1197-1201.

7. Sreedharan A, Harris K, Crellin A, Forman D, Everett SM. Interventions for dysphagia in oesophageal cancer. Cochrane Database Syst Rev 2009;(4):CD005048.

8. Uitdehaag MJ, Siersema PD, Spaander MC, et al. A new fully covered stent with antimigration properties for the palliation of malignant dysphagia: a prospective cohort study. Gastrointest Endosc 2010;71:600605.

9. Talreja JP, Eloubeidi MA, Sauer BG, et al. Fully covered removable nitinol self-expandable metal stents (SEMS) in malignant strictures of the esophagus: a multicenter analysis. Surg Endosc 2012;26:1664-1669.

10. Kim ES, Jeon SW, Park SY, et al. Comparison of double-layered and covered Niti-S stents for palliation of malignant dysphagia. J Gastroenterol Hepatol 2009;24:114-119.

11. Hirdes MM, Siersema PD, Vleggaar FP. A new fully covered metal stent for the treatment of benign and malignant dysphagia: a prospective follow-up study. Gastrointest Endosc 2012;75:712-718.

12. Shim CS, Jung IS, Bhandari S, et al. Management of malignant strictures of the cervical esophagus with a newly-designed self-expanding metal stent. Endoscopy 2004;36:554-557.

13. Shim CS. Esophageal stenting in unusual situations. Endoscopy 2003; 35:S14-S18.

14. Park JJ, Lee YC, Kim BK, et al. Long-term clinical outcomes of self-expanding metal stents for treatment of malignant gastroesophageal junction obstructions and prognostic factors for stent patency: effects of anticancer treatments. Dig Liver Dis 2010;42:436-440.

15. Adler DG, Baron TH. Endoscopic palliation of malignant gastric outlet obstruction using self-expanding metal stents: experience in 36 patients. Am J Gastroenterol 2002;97:72-78.

16. Hirdes MM, Siersema PD, Houben MH, Weusten BL, Vleggaar FP. Stent-in-stent technique for removal of embedded esophageal self-expanding metal stents. Am J Gastroenterol 2011;106:286-293.

17. Didden P, Kuipers EJ, Bruno MJ, Spaander MC. Endoscopic removal of a broken self-expandable metal stent using the stent-in-stent technique. Endoscopy 2012;44 Suppl 2 UCTN:E232.

18. Park SY, Park CH, Cho SB, et al. The usefulness of clip application in preventing migration of self-expandable metal stent in patients with malignant gastrointestinal obstruction. Korean J Gastroenterol 2007; 49:4-9.

19. van Boeckel PG, Sijbring A, Vleggaar FP, Siersema PD. Systematic review: temporary stent placement for benign rupture or anastomotic leak of the oesophagus. Aliment Pharmacol Ther 2011;33:1292-1301.

20. Bick BL, Song LM, Buttar NS, et al. Stent-associated esophagorespiratory fistulas: incidence and risk factors. Gastrointest Endosc 2013;77: 181-189.

21. Verschuur EM, Steyerberg EW, Kuipers EJ, Siersema PD. Effect of stent size on complications and recurrent dysphagia in patients with esoph- ageal or gastric cardia cancer. Gastrointest Endosc 2007;65:592-601.

22. Siersema PD, Hop WC, van Blankenstein M, et al. A comparison of 3 types of covered metal stents for the palliation of patients with dysphagia caused by esophagogastric carcinoma: a prospective, randomized study. Gastrointest Endosc 2001;54:145-153.

23. Sabharwal T, Hamady MS, Chui S, Atkinson S, Mason R, Adam A. A randomised prospective comparison of the Flamingo Wallstent and Ultraflex stent for palliation of dysphagia associated with lower third oesophageal carcinoma. Gut 2003;52:922-926.

24. Conio M, Repici A, Battaglia G, et al. A randomized prospective comparison of self-expandable plastic stents and partially covered self-expandable metal stents in the palliation of malignant esophageal dysphagia. Am J Gastroenterol 2007;102:2667-2677.

25. Verschuur EM, Repici A, Kuipers EJ, Steyerberg EW, Siersema PD. New design esophageal stents for the palliation of dysphagia from esophageal or gastric cardia cancer: a randomized trial. Am J Gastroenterol 2008;103:304-312.

26. van Heel NC, Haringsma J, Boot H, Cats A, Vanhoutvin SA, Kuipers EJ. Comparison of 2 expandable stents for malignant esophageal disease: a randomized controlled trial. Gastrointest Endosc 2012;76:52-58.

27. Zhu HD, Guo JH, Mao AW, et al. Conventional stents versus stents loaded with (125)iodine seeds for the treatment of unresectable oesophageal cancer: a multicentre, randomised phase 3 trial. Lancet Oncol 2014;15:612-619.

28. Pereira-Lima JC, Ramires RP, Zamin I Jr, Cassal AP, Marroni CA, Mattos AA. Endoscopic dilation of benign esophageal strictures: report on 1043 procedures. Am J Gastroenterol 1999;94:1497-1501.

29. Raymondi R, Pereira-Lima JC, Valves A, et al. Endoscopic dilation of benign esophageal strictures without fluoroscopy: experience of 2750 procedures. Hepatogastroenterology 2008;55:1342-1348.

30. Thomas T, Abrams KR, Subramanian V, Mannath J, Ragunath K. Esophageal stents for benign refractory strictures: a meta-analysis. Endoscopy 2011;43:386-393.

31. Dua KS, Vleggaar FP, Santharam R, Siersema PD. Removable self-expanding plastic esophageal stent as a continuous, non-permanent dilator in treating refractory benign esophageal strictures: a prospective two-center study. Am J Gastroenterol 2008;103:2988-2994.

32. Holm AN, de la Mora Levy JG, Gostout CJ, Topazian MD, Baron TH. Self-expanding plastic stents in treatment of benign esophageal conditions. Gastrointest Endosc 2008;67:20-25.

33. Karbowski M, Schembre D, Kozarek R, Ayub K, Low D. Polyflex selfexpanding, removable plastic stents: assessment of treatment efficacy and safety in a variety of benign and malignant conditions of the esophagus. Surg Endosc 2008;22:1326-1333.

34. Kitta Y, Obata JE, Takano H, et al. Echolucent carotid plaques predict in-stent restenosis after bare metal stenting in native coronary arteries. Atherosclerosis 2008;197:177-182.

35. Hirdes MM, Siersema PD, van Boeckel PG, Vleggaar FP. Single and sequential biodegradable stent placement for refractory benign esophageal strictures: a prospective follow-up study. Endoscopy 2012;44: 649-654.

36. Repici A, Conio M, De Angelis C, et al. Temporary placement of an expandable polyester silicone-covered stent for treatment of refractory benign esophageal strictures. Gastrointest Endosc 2004;60:513-519.

37. Brinster CJ, Singhal S, Lee L, Marshall MB, Kaiser LR, Kucharczuk JC. Evolving options in the management of esophageal perforation. Ann Thorac Surg 2004;77:1475-1483.

38. Attar S, Hankins JR, Suter CM, Coughlin TR, Sequeira A, McLaughlin JS. Esophageal perforation: a therapeutic challenge. Ann Thorac Surg 1990;50:45-49.

39. Dechene A, El Fouly AH, Bechmann LP, et al. Acute management of refractory variceal bleeding in liver cirrhosis by self-expanding metal stents. Digestion 2012;85:185-191.

40. Hubmann R, Bodlaj G, Czompo M, et al. The use of self-expanding metal stents to treat acute esophageal variceal bleeding. Endoscopy 
2006;38:896-901.

41. Wright G, Lewis H, Hogan B, Burroughs A, Patch D, O’Beirne J. A selfexpanding metal stent for complicated variceal hemorrhage: experience at a single center. Gastrointest Endosc 2010;71:71-78.

42. Zehetner J, Shamiyeh A, Wayand W, Hubmann R. Results of a new method to stop acute bleeding from esophageal varices: implantation of a self-expanding stent. Surg Endosc 2008;22:2149-2152.

43. Shone DN, Nikoomanesh P, Smith-Meek MM, Bender JS. Malignancy is the most common cause of gastric outlet obstruction in the era of H2 blockers. Am J Gastroenterol 1995;90:1769-1770.

44. Jeurnink SM, Steyerberg EW, van Hooft JE, et al. Surgical gastrojejunostomy or endoscopic stent placement for the palliation of malignant gastric outlet obstruction (SUSTENT study): a multicenter randomized trial. Gastrointest Endosc 2010;71:490-499.

45. van Heek NT, van Geenen RC, Busch OR, Gouma DJ. Palliative treatment in "peri"-pancreatic carcinoma: stenting or surgical therapy? Acta Gastroenterol Belg 2002;65:171-175.

46. Mendelsohn RB, Gerdes H, Markowitz AJ, DiMaio CJ, Schattner MA. Carcinomatosis is not a contraindication to enteral stenting in selected patients with malignant gastric outlet obstruction. Gastrointest Endosc 2011;73:1135-1140.

47. Dormann AJ, Deppe H, Wigginghaus B. Self-expanding metallic stents for continuous dilatation of benign stenoses in gastrointestinal tract - first results of long-term follow-up in interim stent application in pyloric and colonic obstructions. Z Gastroenterol 2001;39:957-960.

48. Binkert CA, Jost R, Steiner A, Zollikofer CL. Benign and malignant stenoses of the stomach and duodenum: treatment with self-expanding metallic endoprostheses. Radiology 1996;199:335-338.

49. Pinto Pabón IT, Díaz LP, Ruiz De Adana JC, López Herrero J. Gastric and duodenal stents: follow-up and complications. Cardiovasc Intervent Radiol 2001;24:147-153.

50. Baron TH, Schöfl R, Puespoek A, Sakai Y. Expandable metal stent placement for gastric outlet obstruction. Endoscopy 2001;33:623-628.

51. Baron TH. Minimizing endoscopic complications: endoluminal stents. Gastrointest Endosc Clin N Am 2007;17:83-104.

52. Hamada T, Nakai $Y$, Isayama $H$, et al. Duodenal metal stent placement is a risk factor for biliary metal stent dysfunction: an analysis using a time-dependent covariate. Surg Endosc 2013;27:1243-1248.

53. Sasaki T, Isayama H, Nakai Y, et al. Clinical outcomes of secondary gastroduodenal self-expandable metallic stent placement by stent-instent technique for malignant gastric outlet obstruction. Dig Endosc 2015;27:37-43.

54. van Hooft JE, Uitdehaag MJ, Bruno MJ, et al. Efficacy and safety of the new WallFlex enteral stent in palliative treatment of malignant gastric outlet obstruction (DUOFLEX study): a prospective multicenter study. Gastrointest Endosc 2009;69:1059-1066.

55. Jeurnink SM, van Eijck CH, Steyerberg EW, Kuipers EJ, Siersema PD. Stent versus gastrojejunostomy for the palliation of gastric outlet obstruction: a systematic review. BMC Gastroenterol 2007;7:18.

56. Masci E, Viale E, Mangiavillano B, et al. Enteral self-expandable metal stent for malignant luminal obstruction of the upper and lower gastrointestinal tract: a prospective multicentric study. J Clin Gastroenterol 2008;42:389-394.

57. Piesman M, Kozarek RA, Brandabur JJ, et al. Improved oral intake after palliative duodenal stenting for malignant obstruction: a prospective multicenter clinical trial. Am J Gastroenterol 2009;104:2404-2411.

58. Khashab M, Alawad AS, Shin EJ, et al. Enteral stenting versus gastrojejunostomy for palliation of malignant gastric outlet obstruction. Surg Endosc 2013;27:2068-2075.

59. Tringali A, Didden P, Repici A, et al. Endoscopic treatment of malignant gastric and duodenal strictures: a prospective, multicenter study. Gastrointest Endosc 2014;79:66-75.

60. Song GA, Kang DH, Kim TO, et al. Endoscopic stenting in patients with recurrent malignant obstruction after gastric surgery: uncovered versus simultaneously deployed uncovered and covered (double) selfexpandable metal stents. Gastrointest Endosc 2007;65:782-787.

61. Kim TO, Kang DH, Kim GH, et al. Self-expandable metallic stents for palliation of patients with malignant gastric outlet obstruction caused by stomach cancer. World J Gastroenterol 2007;13:916-920.

62. Espinel J, Sanz O, Vivas S, et al. Malignant gastrointestinal obstruction: endoscopic stenting versus surgical palliation. Surg Endosc 2006;20: 1083-1087.

63. Maire F, Hammel P, Ponsot P, et al. Long-term outcome of biliary and duodenal stents in palliative treatment of patients with unresectable adenocarcinoma of the head of pancreas. Am J Gastroenterol 2006; 101:735-742.

64. Maetani I, Akatsuka S, Ikeda M, et al. Self-expandable metallic stent placement for palliation in gastric outlet obstructions caused by gastric cancer: a comparison with surgical gastrojejunostomy. J Gastroenterol 2005;40:932-937.

65. Mehta S, Hindmarsh A, Cheong E, et al. Prospective randomized trial of laparoscopic gastrojejunostomy versus duodenal stenting for malignant gastric outflow obstruction. Surg Endosc 2006;20:239-242.

66. Kim JH, Song HY, Shin JH, et al. Metallic stent placement in the palliative treatment of malignant gastroduodenal obstructions: prospective evaluation of results and factors influencing outcome in 213 patients. Gastrointest Endosc 2007;66:256-264.

67. Shaw JM, Bornman PC, Krige JE, Stupart DA, Panieri E. Self-expanding metal stents as an alternative to surgical bypass for malignant gastric outlet obstruction. Br J Surg 2010;97:872-876.

68. van den Berg MW, Haijtink S, Fockens P, et al. First data on the Evolution duodenal stent for palliation of malignant gastric outlet obstruction (DUOLUTION study): a prospective multicenter study. Endoscopy 2013;45:174-181.

69. No JH, Kim SW, Lim CH, et al. Long-term outcome of palliative therapy for gastric outlet obstruction caused by unresectable gastric cancer in patients with good performance status: endoscopic stenting versus surgery. Gastrointest Endosc 2013;78:55-62.

70. Fiori E, Lamazza A, Demasi E, Decesare A, Schillaci A, Sterpetti AV. Endoscopic stenting for gastric outlet obstruction in patients with unresectable antro pyloric cancer. Systematic review of the literature and final results of a prospective study. The point of view of a surgical group. Am J Surg 2013;206:210-217.

71. Nagaraja V, Eslick GD, Cox MR. Endoscopic stenting versus operative gastrojejunostomy for malignant gastric outlet obstruction-a systematic review and meta-analysis of randomized and non-randomized trials. J Gastrointest Oncol 2014;5:92-98.

72. Cho YK, Kim SW, Hur WH, et al. Clinical outcomes of self-expandable metal stent and prognostic factors for stent patency in gastric outlet obstruction caused by gastric cancer. Dig Dis Sci 2010;55:668-674.

73. Jeurnink SM, Steyerberg EW, Hof G, van Eijck CH, Kuipers EJ, Siersema PD. Gastrojejunostomy versus stent placement in patients with malignant gastric outlet obstruction: a comparison in 95 patients. J Surg Oncol 2007;96:389-396.

74. Roy A, Kim M, Christein J, Varadarajulu S. Stenting versus gastrojejunostomy for management of malignant gastric outlet obstruction: comparison of clinical outcomes and costs. Surg Endosc 2012;26:3114-3119.

75. Kim JH, Yoo BM, Lee KJ, et al. Self-expanding coil stent with a long delivery system for palliation of unresectable malignant gastric outlet obstruction: a prospective study. Endoscopy 2001;33:838-842.

76. Shike M, Latkany L, Gerdes H, Bloch AS. Direct percutaneous endoscopic jejunostomies for enteral feeding. Gastrointest Endosc 1996;44: 536-540.

77. Baron TH. Expandable metal stents for the treatment of cancerous obstruction of the gastrointestinal tract. N Engl J Med 2001;344:1681-1687.

78. Choi WJ, Park JJ, Park J, et al. Effects of the temporary placement of a self-expandable metallic stent in benign pyloric stenosis. Gut Liver 2013;7:417-422. 